\title{
Research on the Key Steps of Innovative Design of Museum Cultural Derivatives
}

\author{
Xiaotao $\mathrm{Hu}$ \\ Communication University of China \\ Beijing, China
}

\author{
Zhiqiang Dai* \\ Communication University of China \\ Beijing, China \\ *Corresponding Author
}

\begin{abstract}
Museum Cultural Derivatives belongs to the realm of modern industry products, with the museum cultural connotation as its source of design inspiration, and mechanization and mass production as the main means of producing. To design derivatives that can not only reflect the museum culture, but also satisfy the consumers, designers must attach great importance to designing notions, namely three key steps: the cultural research, the selection and refining of cultural symbol and the cultural transformation of the cultural symbol. Only by mastering these three design steps can we design a truly successful museum cultural derivative.
\end{abstract}

Keywords-museum cultural derivatives; innovative design; cultural transformation

\section{INTRODUCTION}

On March 14, 2014, the state council of China has issued To promote the integration of cultural creativity and design with relevant industries, pointing out that promoting the new and high-end services such as cultural creativity and design services, and promoting in-depth integration with the real economy is a major step to enhance the soft power of a nation and the competitiveness of its industries. Thus it can be seen, promoting the integration of cultural creativity and designing with relevant industries is of vital significance to push forward the transformation of our national economy, and museum cultural derivatives are perfect combinations of museum culture and products designing.

\section{The Definition OF Museum CUltural Derivatives AND ITS CURRENT SITUATION}

Museum Cultural Derivatives, broadly speaking, contains all sorts of products that have materialized the museum cultural connotation, including books, videos, duplicates, handicrafts, clothes, posts, souvenirs and so on. While in a narrow sense, museum cultural derivatives belongs to modern industrial products, with the museum culture connotation as its source of design inspiration, with broadcasting the cultural accumulation as its main aim, and with mechanization and mass production as its main means, it is a major carrier to inherit and spread cultural symbols. As a result, museum cultural derivatives are outcomes of the integration of museum culture with products design and production industries.
As everyone knows, cultural derivatives serve cultural industry. It is an indispensable part in the cultural industry chain, and is also one of the most key parts in the value creation of the chain. For example, Chinese animation film Pleasant Goat and Big Wolf only accounts for $30 \%$ of the total revenue, and the remaining $70 \%$ of the revenue comes from the image authorization of the derivatives. Developed countries in Europe and America all attached great importance to the development and sales of museum cultural derivatives. Nearly each museum would establish specialized cultural products stores, and consider the development link as the most significant part in its cultural activities, thus forming a relatively mature industrial chain and operating mechanism. For example, the French national museum has operated more than forty stores across the nation, with its cultural derivatives ranging from the duplicates of ancient paintings to small staff like key chains, mobile phone chains, silk scarves, glasses, etc, and has an income up to forty million Euros.

In most Chinese museums, however, the development and design of museum cultural derivatives is still in its infancy, generally existing the following problems: firstly, the development and design of cultural derivatives has not set its foot in the unique collection of the particular museum, nor does it dig deep into or make full advantage of the cultural connotation of the collection of cultural relics, most of it still rests on the rubbing and duplications of the cultural relics; secondly, the type of derivatives is limited, there is a lack of connection between the derivative varieties and the products, thus failing to form a sense of series. Therefore, it cannot highlight and strengthen the cultural theme, nor can it arouse consumers' desire to purchase. Again, the derivatives are often roughly-made and simply-packaged. They cannot meet the elegant and exquisite images of the museum collections, causing a low cost performance. As a result, the sales of Chinese museum cultural derivatives are far inferior to those of foreign museums. Take Nanjing Museum as an example, one of the large museums nationwide, it has a collection of up to over 400 thousand relics, but the sales of its cultural derivatives is only hundreds of millions Yuan, far from satisfying the demand of the market. 


\section{KEY STEPS IN THE INNOVATION AND DESIGN OF MuSEUM CUlTURAL DERIVATIVES}

Museum Cultural Derivatives, as mentioned above, belongs to the modern industrial products, so the design of museum cultural derivatives program follows the basic design process of general industrial products, which is the process of materializing the design gland notions. The UK Design Council separates the design process of products into three stages: (1) the conceptual stage: understanding problems and opportunities, analyzing problems and the development strategies, defining the nature of the problems to be solved. (2) The Designing stage: developing the plan, evaluating the plan, refining and perfecting the plan, setting up specifications. (3) The realization stage: model opening and producing, and market feedback.

The difference between the museum cultural derivative and the general product lies in that the cultural factor is a unique element. Basically, the development process of the museum's cultural derivatives is the sublimation and materialization process of the museum's historical and cultural elements in the form of creation. Because of the importance of cultural factors in cultural derivatives, under the premise of realizing the basic function of the products, the derivatives pay more attention to promoting the humanistic value and the emotional demand of the product, making elements like the function, form, semantics of the products perfectly combined. Hence, the innovative design of cultural derivatives must first find the design inspiration from the cultural resources. The following are the key steps that are unique to the conceptual stage in the cultural derivatives designing program.

1) Cultural research: The main contents of cultural research are divided into the following aspects: firstly, the history and orientation of the museum should be understood, and different characteristics should be identified. Secondly, the museum's collections shall be understood as detailed as possible, especially the precious ones that are unique to the museum and can represent its characteristics and positioning, and the story behind them should be dug deeper into. All these are the sources of the design inspiration. For example, the world's top museum, Louvre museum, has a collection that can be roughly divided into seven realms: ancient East, Egypt, Rome art, painting, drawing, sculpture, arts and crafts, with a total number up to hundreds of thousands. The Mona Lisa smile, The Venus DE milo, the Goddess of Victory are its most precious three collections. Finally, you need to sort and delete the materials incurred by the cultural research. Some materials are culturally representative, but not all materials are suitable to be transferred into cultural symbols, nor be further applied to the design of cultural derivatives, in which the designer's experience plays a decisive role.

In the Palace Museum in Taipei, for example, in 20052007, the palace has launched an activity called "old is the new - the fashionable Imperial Palace", one of the more important link is about a creative development plan of cultural derivatives. One participating team is informed during the process of culture research on the Palace Museum that, in the Confucian culture, the ancients would have "jade" personified.
Jade is used to describe or represent one's high-minded character, e.g. "A gentleman is like a jade and is always wearing it on", "the jade is pure and clear", "a piece of ice in the jade pot." The museum has a collection of jade fish from the late Shang dynasty to the western Zhou dynasty. The ancient artists carved out the shape of the fish in a refined and abstract way. Based on the research above, this group of designers produced the design concept of "making an ice box out of fish-like jade". That is to say, to shape the ice box mold as a jade fish, so when water was poured into the ice box and been frozen, a jade fish shaped ice will be formed. And when it was put into the water, it would look like a fish is having a good swim in the water. The product has created such an image and has formed an elegant and sentimental ambiance of life aesthetics.

2) The selection and refinement of cultural symbols: After detailed culture research and a comprehensive and thorough understanding of the positioning, history, and the collections of the museum, we need to extract typical cultural symbols so as to the design of derivatives. Cultural anthropology in the 20th century pointed out that "all cultures, except those in the form of materials, exist in the form of symbols." All human activities originate from symbols and symbols are the foundation of culture. Different social backgrounds and historical cultures create different traditions and thus produce different cultural symbols. For example, in Chinese wooden buildings, forms, of double reeves, vertical ridges, flying wings, brackets arches can all be summarized into a kind of cultural symbols. While considering its social background and its historical culture, these cultural symbols are not natural characteristics of the Han nationality, but a vivid image of specific social relations and mental propensities. Therefore, designers need to select and refine representative cultural symbols that can be easily translated into design languages. Anyhow, the ultimate goal to design museum derivatives is to create impressive symbols with cultural connotation, with a further aim to successfully communicate culture to consumers and get their thoughts on the resonance.

A scholar Yang Jing, for example, in her studies on regional culture in Foshan, Guangdong, has extracted visual symbols with specific regional cultural features from five representative art forms: awake lion, New Year pictures, Cantonese opera, china, and wushu, and then she explains them visually from contents, styles, colors and spirits. In the process of selection and refining, first of all, designers should consider the positioning style of the museum. Since each museum has its own brand culture orientation, we should choose and extract culture symbols according to the consistency of brand culture. Second, we should also consider the types of cultural derivatives matched to the culture symbols. Though the same cultural symbol element can be applied to different product categories, we should have different focus and selection on the culture symbol and the corresponding derivatives. This can be exemplified by a scholar, Zhou Rui. When he has firstly extracted cultural symbols from Sichuan, he intended to apply them to the tablewares of Sichuan Cuisine. In this process, he contends that there are two major steps, namely the selection and the refining to ensure the cultural 
symbols in the design of the tablewares, and should avoid symbols that are conflicting with or are under taboo. Also, we should excluded those that do not meet with the modern consumers' appreciation, those that are difficult to be processed, or those with a high cost and are not suitable to be transferred.

\section{3) Products transferred from cultural symbols}

The product transformation of cultural symbols mainly follows the relevant principles and methods of product semantics. Product semantics studies the world in the cognition of symbols, and is a theory studies the semantics of products language. In this theory, the semantics of products language includes explicit meanings and implicit meanings. The explicit meanings mainly express the physical and physiological functions of the products, such as the texture, color, functions, operations, performance and reliabilities of the products; while the implicit meanings refers to the psychological, social and cultural symbolic meaning revealed in the environment. Specifically, it can be separated into three parts: 1. the motional meanings showed by the products, such as a adorable, elegant and cosy feeling; 2. The consonance given to one's class and social status: each individual belongs to a particular social class, and the products they own will accordingly express their status and class. 3 . The historical and cultural meaning conveyed by products: as John Neil once said, "The object is the trace of culture reserved in its own time and space." For example, in our eyes, the bronze wares in the museum are not just simple living things, but the epitome of the history and culture of the era. The explicit signal of the product is the premise of the existence of hidden signal, but in many cases, the function of implied meaning is often bigger than that of the explicit signal, especially for the design of cultural derivatives. Any clothing, for example, functions to cover the body and protects us from the cold. However, the ancient Chinese imperial dragon robe means more than this," but emphasizes the status and imperial majesty of the imperial by many noble culture symbols. For example, the color of the dragon robe is yellow, with 9 dragons embroidered on , 3 pieces respectively on the front and on the back, 1 on the left and one on the right shoulder, and 1 in the skirt. As a result, there are 5 on both the front and reverse side, which is the symbol of the imperial throne. In Qing dynasty, there are pictures of water, waves, mountains and rocks on the lower hem of the dragon robe, which has an implicit meaning of the union of the country.

To transform the cultural symbols into products, we should first have a thorough understanding of these symbols, and then draw on their figures, extend their meanings, and show their spirits. It's not a simple copy of the cultural symbol, but a recreation in the manner of modern aesthetic ideas on the basis of a comprehensive understanding. We try to find an integrating point between the traditions and the modern times, enshrine the designs of the derivatives with both cultural features and time features. According to the viewpoints of products semantics, emphasis should be put on how to refer to and cite cultural symbols. By means of metaphor, metonymy, synecdoche and allegory, to connect the product with cultural symbols where the derivatives come from.

\section{CONCLUSION}

The value chain of cultural industry is composed of a series of value creation activities which can meet the needs of customers. Among them, the value creation ability of the derivative is often several times stronger than the cultural product itself, making the development of the derivatives an indispensable part in the value chain. Museum Cultural Derivative is not only a vital part in the value creation, or acts only as a media or carrier between the museum culture and its users, but also can it build the brand image of the museum, enhance core competitiveness, advertise the museum culture, and liven the museum collections. Successful museum operations cannot be separated from distinctive, high-level cultural derivative designs.

\section{REFERENCES}

[1] Fei Hu, Rui Yang, Design symbols and product semantics, Beijing: China construction industry press, August 2012, page 128 .

[2] Guoqiang Chen, Product design procedures and methods, Beijing mechanical industry press, July 2011, page 26

[3] Huiyuan Liu, The aesthetic economy of the world's top museums. [J]. Origin press, July 2009.

[4] Jin Qiao, Research on the development and planning of the art derivatives industry in domestic museums, [J].Economic research guide, 2014, 14, p. 57.

[5] Jing Yang, The refinement and presentation of regional cultural visual symbols - a case study of Foshan hand - Han-Tang cake packaging design. [J].Decoration, no. 11, 2012, page 123.

[6] Liangjun Li, Thinking on the design of contemporary cultural creative commodities-Analysis on the teaching practice of lu dingbang. [J] Hubei academy of fine arts, no. 4, 2012, pp. 97-99.

[7] Rui Zhou, The reflection of Sichuan cultural elements in the design of Sichuan dishes. [J].Packaging engineering, no. 9, 2008, p. 140-142.

[8] Shouyao Teng, Artistic sociological description, Nanjing: Nanjing press, January 2006, p. 36

[9] Shuxian Ye, Culture and symbolic economy, Guangzhou: Guangdong people's publishing house, June, 2012, page 9

[10] Tao Gui, Cultural industry value chain cost analysis and derivative development. [J]. The economy of the SAR", 4, 2013, p. 213.

[11] Xiang Huang, Research on the design strategy of "old is new"- fashion palace. Master's thesis, institute of museology, fu ren university, Taiwan, page 87

[12] Yiping Zhang, Understanding and thinking on the development of museum cultural derivative products, [J]. Southern Culture, 5, 2011, page 106 